\title{
Validation of INNWIND.EU Scaled Model Tests of a Semisubmersible Floating Wind Turbine
}

\author{
Christian Koch ${ }^{1}$, Frank Lemmer ${ }^{1}$, Friedemann Borisade ${ }^{1}$, Denis Matha ${ }^{2}$ and Po Wen Cheng ${ }^{1}$ \\ ${ }^{1}$ S tuttgart Wind Energy (SWE), University of Stuttgart, Stuttgart, Germany \\ ${ }^{2}$ Ramboll Wind, Hamburg, Germany
}

\begin{abstract}
The subject of this study is the verification and the validation of existing numerical codes for floating offshore wind turbine structures using wave tank model tests as part of the INNWIND.EU project. A model of the OC4-DeepCwind semisubmersible platform, together with a Froude scaled rotor model with low-Reynolds airfoils is tested in a combined wind-and-wave basin. The simulation environment comprises the multibody software SIMPACK with the HydroDyn module for the hydrodynamic loads, MAP++ for the mooring line forces and AeroDyn for the aerodynamic loads. The focus of this paper is the validation of the hydrodynamics of a modified model hull shape, which compensates for the excess mass of the nacelle. Furthermore also first steady wind simulations without wave excitation have been carried out. The results show that the model is validated and gives the basis for further research based on the conducted experiments.
\end{abstract}

KEYWORDS: INNWIND.EU; floating wind turbine; semisubmersible platform; hydrodynamics; simulation; wave tank test.

\section{INTRODUCTION}

The theoretical potential of offshore wind energy can be estimated to $192,800 \mathrm{TWh}$ where more than $52 \%$ of the energy potential is located in areas with water depths from 50 to $200 \mathrm{~m}$ (Arent et al., 2012). To be able to use this potential with respect to financial and commercial aspects new foundation systems for the wind turbines have to be applied. With higher water depths the use of floating structures is more reasonable than fixed bottom structures such as monopiles, tripods and jackets (Musial et al., 2006).

A floating wind turbine experiences many different loading conditions. Besides the aerodynamic loads, hydrodynamic loads the six DOFs floater motion has to be considered. A floating wind turbine is therefore a very complex system. Until now not many floating offshore wind turbine prototypes have been built. For example the Fukushima Forward-Project which started 2013 (Fukushima Offshore Wind Consortium, 2016) and the Hywind Scotland Pilot Park project (Statoil ASA, 2014) can be listed as current floating turbine prototypes.
In order to design wind turbines with high reliabilities for floating offshore turbines there is the need for validated simulation codes to predict the forces on the system structure and their dynamic responses for combined stochastic wave and wind loadings (Musial et al., 2006). Even though several verification test for the simulation tools have been done e.g. Robertson et al. (2013), Huijs et al. (2014), the simulation of the coupled floating wind turbine is still a part of current research projects. The research which is reported in Deliverable D4.2.4 of the INNWIND.EU project (Lemmer et al., 2014) focuses on the verification and validation of design methods for floating structures.

The task 4.2 of INNWIND.EU with its test campaign at LHEEA, Ecole Centrale de Nantes (ECN) (France) in 2014 has the goal of increasing the experience with scaled experiments, reducing the uncertainty in the results and producing another dataset of the well-known OC4-DeepCwind semisubmersible together with a performance-scaled 10MW rotor. The concept has been used in previous research and it has been tested at MARIN in Wageningen (Netherlands) by the DeepCwind consortium in 2011, see Jain et al. (2012), Coulling et al. (2013) and Robertson et al. (2013). The same model has been tested again at MARIN in 2013 with detailed analyses of the secondorder wave excitation forces and the aerodynamics at low Reynolds numbers, see Kimball et al. (2014), Ridder et al. (2014), Make et al. (2015), Gueydon et al. (2014), Gueydon (2015), Gueydon et al. (2015), and Gueydon (2016). Currently, within the activities of IEA wind task 30, the OC5 consortium (Offshore Code Comparison Collaboration Continuation with Correlation) uses the measurement data from MARIN for a joint validation task.

In this research, a scaled $10 \mathrm{MW}$ model of the OC4-DeepCWind semisubmersible (Robertson et al., 2014), built at the University of Stuttgart and a Froude scaled wind turbine with low-Reynolds rotor blades developed by Politechnico di Milano is used.

For the simulation of the whole system including the platform and the wind turbine the commercial Multibody System (MBS) tool SIMPACK is used. The hydrodynamic forces are calculated by the 
software package HydroDyn (Jonkman et al., 2013), which is coupled to MBS. For the calculation of the frequency dependent values as the hydrodynamic added-mass and the additional damping from the radiation problem as well as the frequency and direction dependent first order wave-excitation force from the linear diffraction problem and for the calculation of the hydrostatic data ANSYS AQWA is used in a pre-processing step. The modelling of the mooring lines is implemented by the MAP++ module, which is coupled to MBS. For the aerodynamic loads the software package AeroDyn (Craig and Laino, 2002) is used, which is as well coupled to the MBS.

In this research pitch free decay tests as well as wave-only and wind-only tests are examined. First of all the experimental and the simulation setup are described. In the data section the free decay test, the waves only test and the wind only test comparison is shown with a followed discussion of the results.

\section{EXPERIMENTAL SETUP}

The scaled model tested within the wind and wave tank represents a $10 \mathrm{MW}$ semi-submersible floating wind turbine. The $10 \mathrm{MW}$ model was developed based on the up-scaling of a $5 \mathrm{MW}$ model. In order to obtain a equivalent dynamic behaviour between the model and the full scale system Froude scaling is used. The scaling laws can be found in Bredmose et al. (2012). The geometry and the mass distribution of the model is aligned with the $5 \mathrm{MW}$ DeepCwind semi-submersible presented by Robertson et al. (2014) with a scaling factor of $\lambda_{1}=1 / 45$. The scaled model with $\lambda_{1}$ is then up scaled with a scaling factor $\lambda_{2}=1 / 60$ to hold the $10 \mathrm{MW}$ INNWIND.EU wind turbine. In Table 1 the ideal scaled system parameters are summarized.

Table 1 Ideal properties of baseline and scaled systems

\begin{tabular}{|l|l|l|l|}
\hline Target Property & $\begin{array}{l}\text { Baseline } \\
\text { 5MW } \\
\text { Turbine } \\
\lambda_{1}\end{array}$ & $\begin{array}{l}\text { INNWIND.EU } \\
\text { 10MW Proto- } \\
\text { type } \lambda_{2}\end{array}$ & $\begin{array}{l}\text { Scaled } \\
\text { Model }\end{array}$ \\
\hline Overall Mass including ballast $[\mathrm{kg}]$ & $1.41 \mathrm{E} 7$ & $3.34 \mathrm{E} 7$ & 150.39 \\
\hline Platform Mass including ballast $[\mathrm{kg}]$ & $1.348 \mathrm{E} 7$ & $3.20 \mathrm{E} 7$ & 144.06 \\
\hline Overall CM location below SWL $[\mathrm{m}]$ & 9.893 & 13.19 & 0.22 \\
\hline System roll inertia about overall CM $\left[\mathrm{kgm}^{2}\right]$ & $1.13 \mathrm{E} 10$ & $4.76 \mathrm{E} 10$ & 59.64 \\
\hline System pitch inertia about overall CM $\left[\mathrm{kgm}^{2}\right]$ & $1.13 \mathrm{E} 10$ & $4.76 \mathrm{E} 10$ & 59.64 \\
\hline System yaw inertia about overall CM $\left[\mathrm{kgm}^{2}\right]$ & $1.23 \mathrm{E} 10$ & $5.18 \mathrm{E} 10$ & 64.91 \\
\hline
\end{tabular}

\section{Platform}

The platform consists of 3 columns with an angular distance of $120 \mathrm{deg}$ and one main column where the wind turbine is mounted, see Fig. 1.

The columns itself are connected via cross braces to achieve stability and structural integrity. Below the outer columns heave plates are mounted. However, because of the additional sensors and cables as well as the higher nacelle mass, the overall center of gravity (COG) between the ideally scaled model and the constructed mock-up does not match in vertical direction. For compensation additional ballast is added below the platform. Therewith a center of gravity of $-0.216 \mathrm{~m}$ below SWL can be achieved, which is just slightly above the scaled value of $-0.22 \mathrm{~m}$. During the construction of the model by Amann (2014) the vertical position of the cross braces which connect the heave plates to the main column is slightly changed due to manufacturing issues. A comparison of the original OC4 DeepCWind semi-submersible to the in the INNWIND.EU tests used platform is represented in the following Fig. 2.

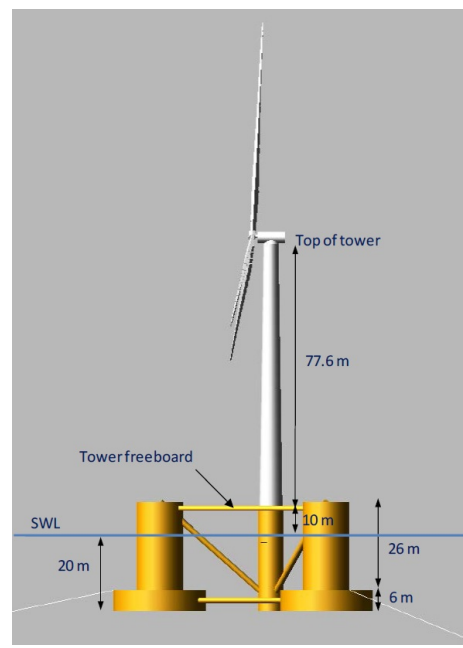

Fig. 1 OC4 DeepCwind semisubmersible design Robertson et al. (2014)

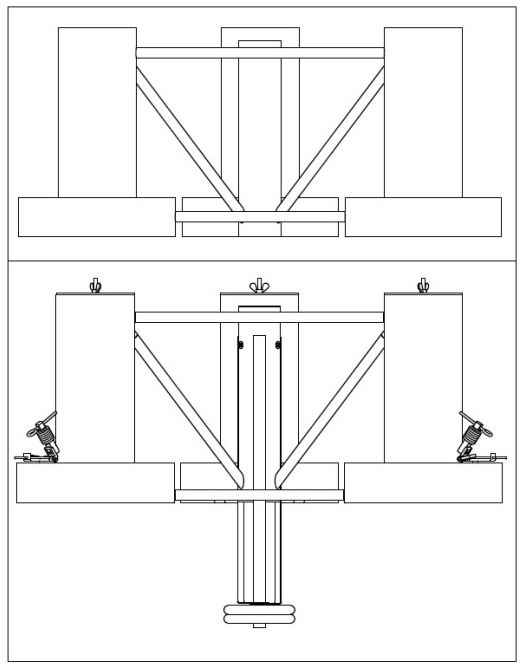

Fig. 2 Original OC4 (top) and scaled INNWIND.EU (bottom) platform model

\section{Wind turbine}

Based on the Froude scaling the correct aerodynamic behaviour cannot be maintained because the Reynolds number ratio is different between model and full scale system. To achieve representative rotor loads within the test a low Reynolds rotor with special air foil shape is designed and built by Politecnico di Milano. This special rotor is designed to scale the thrust force correctly, because this is the main factor on the overall loads and dynamic behaviour of the rotor. The effects by correct torque and therefore power where only of second priority for which reason both cannot be used properly to predict their full scale characteristics.

For the test cases without wind only the blade mass and the blade inertias as well as the center of gravity are taken into account. The mass of the constructed rotor-nacelle-assembly is higher than the ideally scaled one due to the installation of sensors and increased chord length of the airfoils. The main parameters of the Froude scaled rotor blade are summarized in Table 2. In Fig. 3 the varying balde chord as well as the blade twist over the rotor length are visualised. 
Table 2 Parameters of the Froude scaled low-reynolds rotor

\begin{tabular}{|l|l|}
\hline Parameter & Value \\
\hline Rotor radius $[\mathrm{m}]$ & 1.4 \\
\hline Root length $[\mathrm{m}]$ & 0.054 \\
\hline Rated rotor speed $[\mathrm{rpm}]$ & 9.893 \\
\hline Rated rotor torque $[\mathrm{Nm}]$ & 0.83 \\
\hline Rated rotor thrust $[\mathrm{N}]$ & 8.779 \\
\hline Optimal tip speed ratio $(\mathrm{TSR})[-]$ & 7 \\
\hline Blade Chord @ 0.5 $r / R[\mathrm{~m}]$ & 0.154 \\
\hline Airfoil & RG14 \\
\hline Pitch angle at $v_{\text {rated }}[\mathrm{deg}]$ & 4 \\
\hline Re @ 0.5 $\frac{r}{R}$ and $v_{\text {rated }}[-]$ & $6 \mathrm{E} 4$ \\
\hline Nacelle tilt $[\mathrm{deg}]$ & 6 \\
\hline Rotor pre-cone $[\mathrm{deg}]$ & -2.5 \\
\hline Total blade mass $[\mathrm{kg}]$ & 0.85 \\
\hline Blade inertia about rotor axis $\left[\mathrm{kgm}^{2}\right]$ & 0.191 \\
\hline Blade center of gravity along blade span $[\mathrm{m}]$ & 0.485 \\
\hline
\end{tabular}
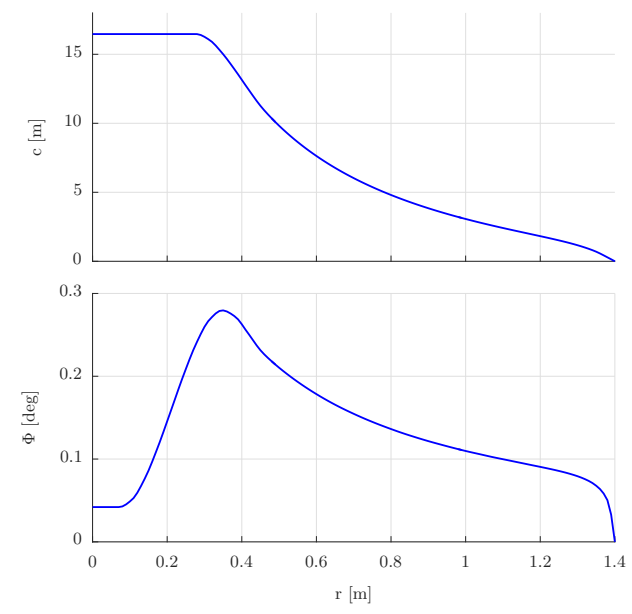

Fig. 3 top: Blade chord over blade length; bottom: Blade twist over blade length

\section{Mooring lines}

The mooring line consists of a stud-less chain of DIN 763 with a wire diameter of $2 \mathrm{~mm}$ and a link length of $22 \mathrm{~mm}$. The main task of the mooring lines is to keep the platform in the position and to damp the motion of the whole system. To achieve this task the semisubmersible is fixed with 3 mooring lines, with an offset of $120 \mathrm{deg}$ between them. The basic layout and numbering of the lines is shown in Fig. 4.

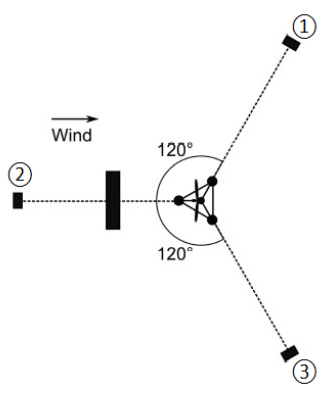

Fig. 4 Mooring system arrangement

Based on the geometry of the wave tank it was not possible to test the platform with the correct Froude scaled line characteristics. Based on the $10 \mathrm{MW}$ design the full scale water depth is $266 \mathrm{~m}$. The scaled $5 \mathrm{MW}$ design has a water depth of $4.444 \mathrm{~m}$. However the dimensions of the wave tank allow an effective water depth of $5 \mathrm{~m}$. The ideal main dimensions of the mooring system are summarized in Table 3.

Table 3 Mooring line main properties

\begin{tabular}{|l|l|l|l|}
\hline Target Property & $\begin{array}{l}\text { Baseline } \\
\text { 5MW } \\
\text { Turbine } \lambda_{1}\end{array}$ & $\begin{array}{l}\text { INNWIND.EUScaled Model } \\
\text { 10MW Pro- } \\
\text { totype } \\
\lambda_{2}\end{array}$ & \\
\hline $\begin{array}{l}\text { Radial distance to the fair- } \\
\text { leads [m] }\end{array}$ & 40.868 & 54.49 & 0.908 \\
\hline Draft of the fairleads [m] & 14 & 18.67 & 0.311 \\
\hline $\begin{array}{l}\text { Radial Distance of the an- } \\
\text { chors [m] }\end{array}$ & 837.6 & 1116.8 & 18.613 \\
\hline Depth of the anchors [m] & 200 & 266.67 & 4.444 \\
\hline
\end{tabular}

Because of the difference between the scaled and the actual water depth of the wave tank the mooring system has to be redesigned in order to achieve the correct force-displacement relationship. This has been done by keeping the model chain properties fixed while changing the unstreched line length as shown in Fig. 5.

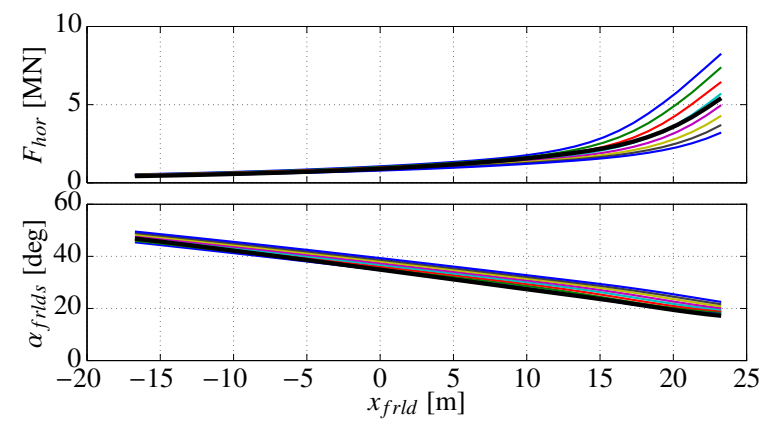

Fig. 5 Mooring line force displacement for $L=773 \ldots 780 \mathrm{~m}$; black: target characteristics; torquoise: selected length $L^{*}=776 \mathrm{~m}$

The resulting actual mooring line dimensions and characteristics used inside the tests can be obtained from Table 4 .

Table 4 Mooring system properties

\begin{tabular}{|l|c|c|c|}
\hline Parameter & Line 1 & Line 2 & Line 3 \\
\hline Anchors radial position [m] & \multicolumn{3}{|c|}{17.11} \\
\hline Fairleads radial position [m] & \multicolumn{3}{|c|}{0.908} \\
\hline Angular position of anchors [deg] & $180^{\circ}$ & $60^{\circ}$ & $300^{\circ}$ \\
\hline Angular position of fairleads [deg] & $180^{\circ}$ & $60^{\circ}$ & $300^{\circ}$ \\
\hline Depth of anchors [m] & \multicolumn{3}{|c|}{5.0} \\
\hline Draft of fairleads [m] & \multicolumn{3}{|c|}{0.311} \\
\hline Mean unstreched length of the lines [m] & \multicolumn{3}{|c|}{17.276} \\
\hline Chain wire diameter [m] & \multicolumn{3}{|c|}{0.002} \\
\hline Mass density in air [kg/m] & \multicolumn{3}{|c|}{0.062} \\
\hline Equivalent hydrodynamic diameter [m] & \multicolumn{3}{|c|}{0.032} \\
\hline
\end{tabular}

\section{Sensors}

During the test various sensors and different data loggers are used. To assure that the measurements start at the same time a common trigger signal was used for all sensors. The main measurement rate is set to $100 \mathrm{~Hz}$. 


\section{Motion tracking}

To measure the motion of the platform a redundant system of a optical motion tracking and inertial measurement unit sensors is implemented. The motion tracking system uses infrared flashes to illuminate small light spheres to measure the displacement of the platform in the wave and wind tank. For this purpose 4 spheres in different positions are used in order to increase the accuracy. The data from the inertial measurement unit is only considered as a backup system for the motion tracking system data. The accuracy of the visual motion tracking system is $1.2 \mathrm{~mm}$, respectively $\sim 0.08 \mathrm{deg}$.

\section{Fairlead sensors}

To measure the fairlead tensions the platform is equipped with three beam cells. Because these cells can only measure the vertical forces lugs were mounted at the platform were the fairleads are attached in full scale conditions. To connect the steel chains with the sensors strings were attached. The construction can be seen schematically in Fig. 6. The length of the portion string is varying slightly for the 3 sensors due to the attachment to the actual mooring lines by hand (\#1 to \#3). Using such sensors avoids in-line sensors, which are significantly heavier than the chain and therefore alter the static and dynamic mooring line properties.

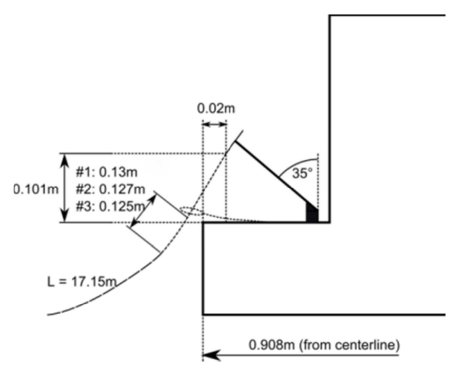

Fig. 6 Fairlead sensor schematic

\section{Wave Probes}

The waves are measured using three different wave probes (WP\#2, WP\#3, WP\#4) which are illustrated in Fig. 7.

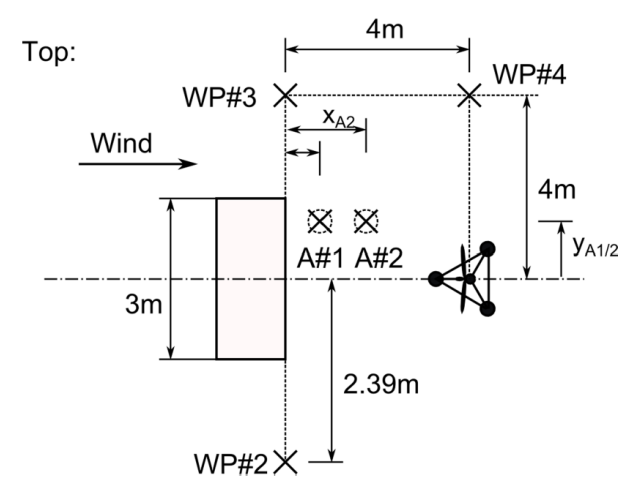

Fig. 7 Wave probes arrangement

\section{Wind Measurement}

In the wave basin two cup anemometers (A\#1 and A\#2) are installed as shown in Fig. 7 in different heights in front of the wind outlet. For the performed simulations previously calibrated fan settings were used. For test week 3 beside of the two cup anemometers also a ultrasonic device is used in order to carry out detailed measurements for the jet and its boundary layers from the wind outlet of the fans for followed CFD simulations (Lemmer et al., 2014).

\section{Other Measurement equipment}

The wind turbine itself is equipped with several sensors such as blade pitch angle, rotor speed, power, shaft bending moment about the rotating nodding and yaw axes, generator torque, rotor azimuth angle and tower base fore-aft and side-side bending moment.

\section{System properties of test model}

During the four week test campaign different mock-ups have been tested. In this study test week two and three are considered in which the Froude scaled rotor mounted to the scaled platform is tested. The model scale system has the overall structural properties shown in Table 5. The overall system in the wave tank is shown in Fig. 8. In week one only the platform is investigated, in week four a ducted-fan by CENER is evaluated.

Table 5 System properties of test mock-up

\begin{tabular}{|l|c|}
\hline Parameter & Testweek 2/3 \\
\hline Overall mass, including ballast [kg] & 155.05 \\
\hline Platform mass, including ballast [kg] & 143.50 \\
\hline Overall CM location below SWL [m] & 0.216 \\
\hline $\begin{array}{l}\text { System roll inertia about overall CM (includ- } \\
\left.\text { ing shifted ballast and WT) [kgm }{ }^{2}\right]\end{array}$ & 77.57 \\
\hline $\begin{array}{l}\text { System pitch inertia about overall CM (in- } \\
\text { cluding shifted ballast and WT) }\left[\mathrm{kgm}^{2}\right]\end{array}$ & 77.29 \\
\hline $\begin{array}{l}\text { System yaw inertia about overall CM (includ- } \\
\text { ing shifted ballast and WT) }\left[\mathrm{kgm}^{2}\right]\end{array}$ & 55.00 \\
\hline
\end{tabular}

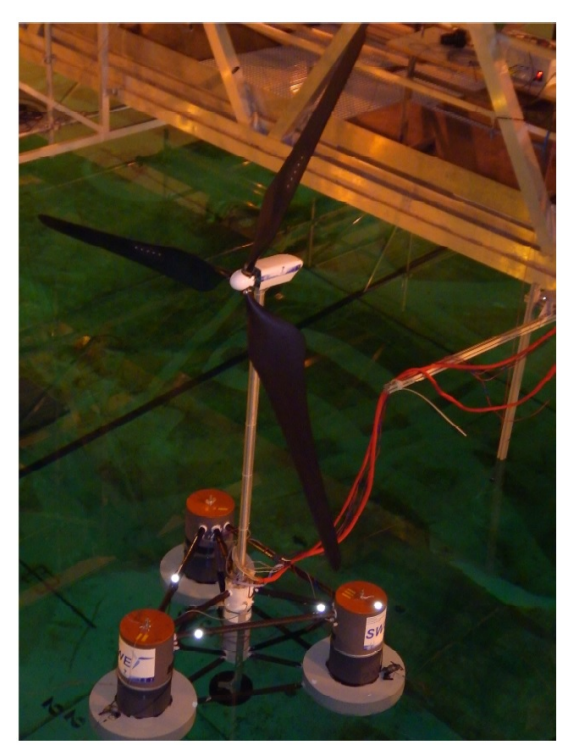

Fig. 8 Mock-up of testweek two/three in the wave tank

\section{SIMULATION SETUP}

The numerical model is described in the following.

\section{Structural dynamics}

The wind turbine model is represented by multiple bodies inside the MBS tool. They are connected via joints and kinematic constraints with different degrees of freedom. Force elements acting on the bodies (e.g. 
wind or wave forces) in the inertial system or in between bodies (such as spring-damper elements) can be used to simulate internal and external loads. Rigid and modally reduced flexible bodies can be implemented. For the calculation of the flexible parts Euler-Bernoulli or Timoshenko beam elements can be applied. In this study only the tower is flexible because the construction and design of the blades can be considered as rigid.

For the tower structure the SIMBEAM module with a node-base non-linear finite difference approach is used to consider its flexibility. For the calculation the shear-deformable model of Timoschenko is selected with a discretisation of ten nodes. Within the calculation only the first and second fore-aft and side-side tower eigenfrequencies are considered.

In Fig. 9 the overall system of the platform and the wind turbine is shown.

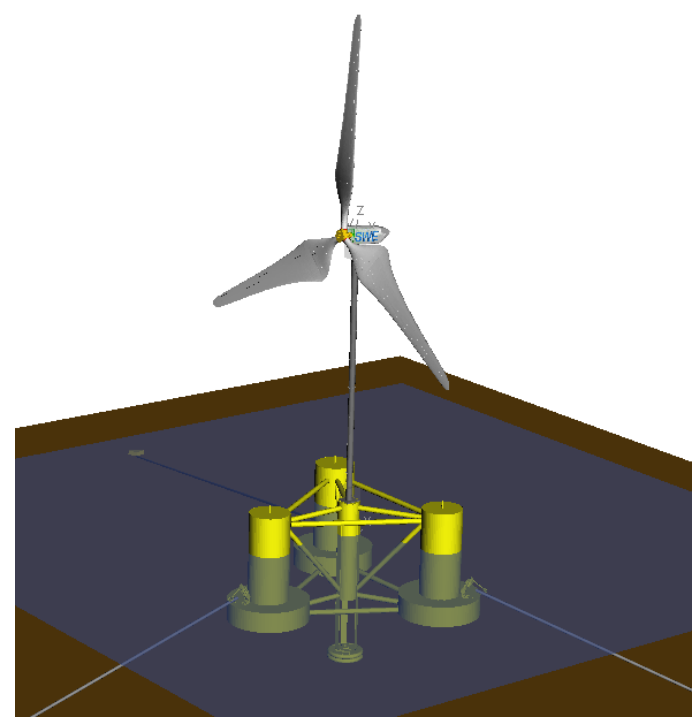

Fig. 9 SIMPACK Model

\section{Hydrodynamics}

The subroutine package HydroDyn is coupled to MBS for the simulation of the hydrodynamic forces. In HydroDyn contributions from linear hydrostatic restoring, nonlinear viscous drag out of the Morison equation, added mass and damping from linear wave radiation (with free-surface memory effects) as well as the incident wave excitation out of linear diffraction are taken into account (Jonkman et al., 2013).

The original hydrodynamic properties of the OC4-DeepCwind platform are not used to simulate the system behaviour due to differences in the sensor mass and additional ballast below the platform. Therefore, a new geometry is built up in CAD to take the changes into account. The diffraction problems as well as the linearised radiation for the new geometry of the floating platform are calculated by using the potential theory program ANSYS AQWA.

The AQWA simulations have been done for 37 different wave directions and 45 different frequencies starting from $0.05 \mathrm{rad} / \mathrm{s}$ in interval steps of $0.079 \mathrm{rad} / \mathrm{s}$. The second-order potential-flow solution is not solved for here. The geometry is simplified to keep the number of node elements below the maximum available number in AQWA of 40.000.
All the cross braces are taken into account as well as the added ballast and its fixation below the platform and the simplified fairlead sensors on top of the heave plates to measure the mooring line forces. In Fig. 10 simplifications of the model are shown.

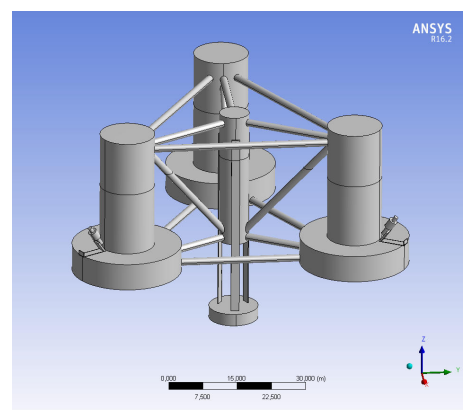

Fig. 10 AQWA platform geometry

The main hydrostatic restoring properties are summarized in Table 6 . These are only the contributions from buoyancy and water plane area.

Table 6 Main hydrostatic restoring values

\begin{tabular}{|l|c|}
\hline Hydrostatic restoring & Value \\
\hline Hydrostatic restoring in heave $\mathrm{C}_{33}[\mathrm{~N} / \mathrm{m}]$ & 1837.818 \\
\hline Hydrostatic restoring in roll $\mathrm{C}_{44}[\mathrm{Nm} / \mathrm{rad}]$ & -114.522 \\
\hline Hydrostatic restoring in pitch $\mathrm{C}_{55}[\mathrm{Nm} / \mathrm{rad}]$ & -114.522 \\
\hline
\end{tabular}

For the infinite frequency the following added mass matrix Eq. 1 is obtained

$$
A_{\text {INNWIND } \infty}=\left(\begin{array}{cccccc}
72.92 \mathrm{~kg} & 0 & 0 & 0 & -21.27 \mathrm{kgm} & 0 \\
0 & 72.86 \mathrm{~kg} & 0 & 21.31 \mathrm{kgm} & 0 & 0 \\
0 & 0 & 161.65 \mathrm{~kg} & 0 & 0 & 0 \\
0 & 21.28 \mathrm{kgm} & 0 & 38.50 \mathrm{kgm}^{2} & 0 & 0 \\
-21.30 \mathrm{kgm} & 0 & 0 & 0 & 38.47 \mathrm{kgm}^{2} & 0 \\
0 & 0 & 0 & 0 & 0 & 24.90 \mathrm{kgm}^{2}
\end{array}\right) \text { (1) }
$$

The added mass matrix for infinite frequency of the Froude scaled original DeepCWind semisubmersible (Robertson et al., 2014) is

$$
A_{O C 4 \text { scaled } \infty}=\left(\begin{array}{cccccc}
69.36 \mathrm{~kg} & 0 & 0 & 0 & -20.21 \mathrm{kgm} & 0 \\
0 & 69.36 \mathrm{~kg} & 0 & 20.21 \mathrm{kgm} & 0 & 0 \\
0 & 0 & 157.1 \mathrm{~kg} & 0 & 0 & 0 \\
0 & 20.21 \mathrm{kgm} & 0 & 38.05 \mathrm{kgm}^{2} & 0 & 0 \\
-20.21 \mathrm{kgm} & 0 & 0 & 0 & 38.05 \mathrm{kgm}^{2} & 0 \\
0 & 0 & 0 & 0 & 0 & 25.70 \mathrm{kgm}^{2}
\end{array}\right)
$$

The values of the added mass for infinite frequency of the INNWIND.EU platform are in average $3.36 \%$ larger than the original scaled OC4 geometry values. In Fig. 11 and 12 the added mass and the hydrodynamic damping coefficients are plotted together with also the hydrostatic restoring in roll and pitch from the original OC4 hull Froude scaled values.

During the free decay simulation test it is observed that the calculated hydrostatic values do not match the measured damping values because the viscous drag is underestimated in the AQWA computation. Therefore an additional damping term is implemented in the HydroDyn input file for $B_{55}$. The free-decay tests have been compared to the theoretical model properties. Subsequently, additional stiffness and damping terms have been identified in order to find the best match. During an optimisation the following terms have been selected, which are summarized in Tab 7.

\section{Mooring Lines}

For the modelling of the mooring lines the simulation software MAP++ of version 1.10.0rc. is used. The Map++ routine is based on a quasi-static model, which ignores the fluid drag loads and the inertia 

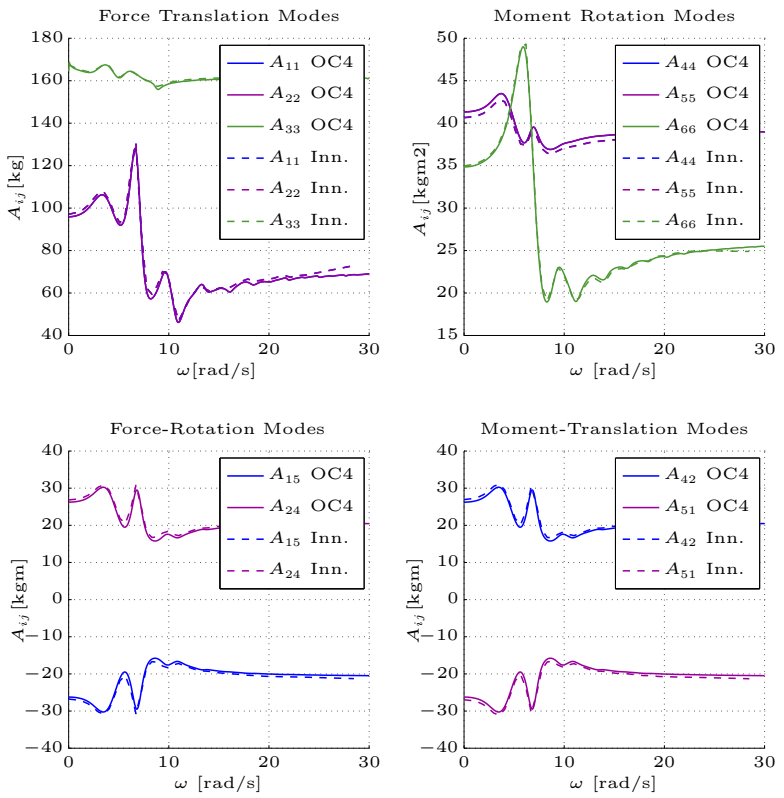

Fig. 11 Added mass coefficients (The values disguised by legend entries are nearly constant)
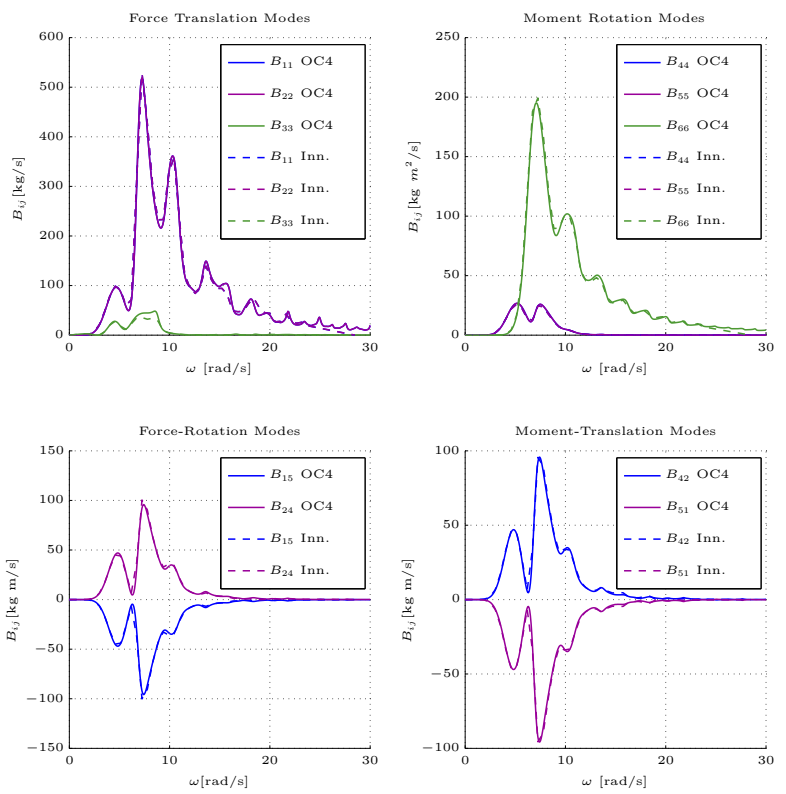

Fig. 12 Hydrodynamic damping coefficients

Table 7 Additional tuning terms

\begin{tabular}{|l|c|}
\hline Tuned parameters & Value \\
\hline Additional Damping in Pitch $\mathrm{B}_{55}$ & $+3.25 \mathrm{~kg} / \mathrm{s}$ \\
\hline Additional Hydrostatic Restoring in Roll $\mathrm{C}_{44}$ & $+14.5 \mathrm{Nm} / \mathrm{rad}$ \\
\hline Additional Hydrostatic Restoring in Pitch $\mathrm{C}_{55}$ & $+14.5 \mathrm{Nm} / \mathrm{rad}$ \\
\hline
\end{tabular}

forces and only includes the forces such as elasticity, line weight in the fluid and geometric nonlinearities.The classic single line closed-form solution is reformulated into a piece-wise multi-segmented system for more flexibilty (Masciola, 2016).

The axial stiffness is calculated based on DNV-GL Offshore Standard (DNV-GL, 2013). From there the Young's Modulus remains as

$E=(5.40-0.040 \cdot d) \cdot 10^{10} \mathrm{~N} / \mathrm{m}^{2}$.

The chain of $2 \mathrm{~mm}$ is upscaled with a factor of 60 as input into the formula. Froude scaling is then used to achieve the correct axial stiffness in model scale. As cross-sectional area twice the diameter of the chain wire has to be used, which leads to a value of $E A=5654.36 \mathrm{~N}$.

The axial stiffness needs to be applied properly. During sensitivity tests it was found out that the axial stiffness has tremendous effects on the line forces, which are applied on the platform, also just little changes on the radial anchor position can lead to a strong influence on the calculated line forces. During the test cases in the wave and wind tank also static mooring line test have been done were the mooring line forces have been measured. Based on this data a comparison of the measured and Map++ calculated forces at the fairlead sensors is done and presented in Table 8 and Table 9.

Table 8 Forces fairlead 1

\begin{tabular}{|l|c|c|c|}
\hline \multirow{2}{*}{ Displacement } & \multicolumn{3}{|c|}{ Fairlead 1 } \\
& Test Case [N] & Simulation [N] & Deviation [\%] \\
\hline Displacement 1 & 9.333 & 9.919 & +6.282 \\
\hline Displacement 2 & 8.492 & 8.989 & +5.853 \\
\hline Displacement 3 & 8.246 & 8.654 & +4.946 \\
\hline Displacement 4 & 8.155 & 8.526 & +4.548 \\
\hline
\end{tabular}

Table 9 Forces fairlead 3

\begin{tabular}{|l|c|c|c|}
\hline \multirow{2}{*}{ Displacement } & \multicolumn{3}{|c|}{ Fairlead 3 } \\
& Test Case [N] & Simulation [N] & Deviation [\%] \\
\hline Displacement 1 & 9.289 & 8.466 & -8.864 \\
\hline Displacement 2 & 8.264 & 7.680 & -7.067 \\
\hline Displacement 3 & 7.869 & 7.370 & -6.342 \\
\hline Displacement 4 & 7.701 & 7.243 & -5.957 \\
\hline
\end{tabular}

Fairlead sensor 2 logged erroneous data and cannot be taken into account for the mooring line validations. But with respect to fairlead sensor 1 and 3 it can be stated that the mooring line simulation shows plausible results. The deviations for sensors 1 and 2 might be explained by an incorrect position of their anchors. In sensitivity tests it is found out that a slight change of the anchor radial position of $0.35 \%$ to $17.05 \mathrm{~m}$ leads to a mean decrease of $6.967 \%$ of the deviation. During the test slight changes of the mooring line system regarding to the unstreched line length and the fairlead sensor position take place which have been always to be taken into account properly because of the mentioned sensitivity to changes of the mooring system.

\section{Aerodynamics}

For the simulation of the wind loads AeroDyn v13.00.00 is coupled to the MBS. AeroDyn is using the BEM theory for the calculation of the wind loads (Moriarty and Hansen, 2005). The blade is discretised with 39 not equally spaced blade elements. To get reasonable results air tables with the specific aerodynamic behaviour for the different blade sections are used based on the work of Politecnico di Milano (Lemmer et al., 2014). Only the Prandtl correction factors for the hub and tip loss are considered within the simulation. In the first calculations no tower shadow correc- 
tion factors are applied furthermore here only the steady dynamic stall model is used.

\section{TEST CASES}

First of all platform only tests were done in order to proof the functionality of the measurement equipment. The second part of the tests was carried out with the wind turbine mounted on the platform. With this configuration first free decay tests have been performed with and without attached mooring lines. After that first waves regular and irregular were tested without wind. At the end of the tests in the wind and wave tank combined wind and wave tests and extreme and survival tests have been carried out. In this paper pitch free decay tests, a regular wave and irregular wave test with mounted wind turbine and attached mooring lines without wind loads are investigated. Furthermore also one test with steady wind and no waves is investigated. All the raw data is filtered using a design low pass filter of the Butterworth IIR type in Matlab with the following parameters to filter out measurement noise. The normalized frequency at the start of the pass band is set to $0.15 \pi \mathrm{rad} / \mathrm{sample}$, the normalized frequency at he end of the stop band is set to $0.2 \pi \mathrm{rad} / \mathrm{sample}$. The allowed amount of ripple in the pass band is set to $1 \mathrm{~dB}$ and the attenuation in the stop band is set to $20 \mathrm{~dB}$.

\section{Pitch free decay}

To place the model in its initial condition for the pitch free decay tests a rope is attached to the center of gravity of the overall system. At the begin of the test case the rope was pulled by hand. The initial conditions are therefore varying. Following test cases were logged as shown in Fig. 10.

Table 10 Pitch free decay tests data

\begin{tabular}{|l|c|c|}
\hline Testcase & Initial Pitch Position [deg] & Time Measured [s] \\
\hline Pitch free decay 1 & -4.86 & 49.53 \\
\hline Pitch free decay 2 & 1.82 & 44.88 \\
\hline Pitch free decay 3 & -2.83 & 45.99 \\
\hline Pitch free decay 4 & 0.667 & 51.6 \\
\hline Pitch free decay 5 & -2.23 & 27.84 \\
\hline
\end{tabular}

In Fig. 13 the values for all the measured eigenfrequencies, logarithmic decrements and damping ratios are shown. The pitch free decay test number four can only be considered for the calculation of the mean frequency of oscillation but not for the damping terms because its initial condition with $0.0667 \mathrm{deg}$ is too small and therefore delivers not reasonable results.

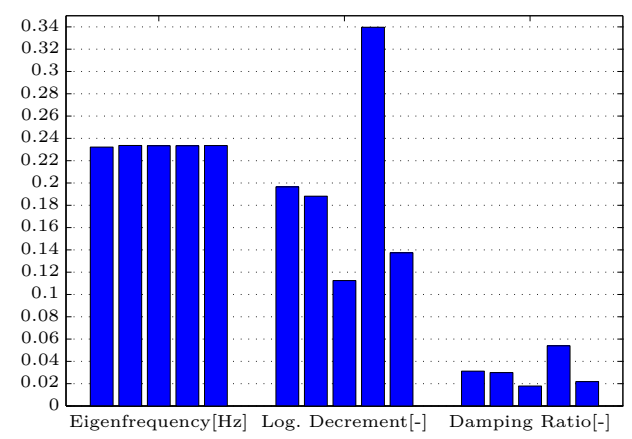

Fig. 13 Pitch free decay eigenfrequencies and damping characteristics

\section{Waves only}

First, waves with small wave heights were investigated with the intention to minimize the influence of the second order effects. However, during the data preparation and the first simulations it is experienced that the measurement noise influence for the small wave heights is not negligible because of the minor motions of the platform e.g. for a significant wave height of $0.046 \mathrm{~m}$ a maximal deflection of $0.15 \mathrm{deg}$ in pitch direction is observed. Therefore in the following larger wave heights were examined. In Table 11 the investigated wave load cases are summarized.

Table 11 Load cases waves only

\begin{tabular}{|l|c|c|c|}
\hline Testcase & $\begin{array}{l}\text { Significant wave } \\
\text { height } H_{s}[\mathbf{m}]\end{array}$ & Period $T_{p}[\mathbf{s}]$ & Gamma [-] \\
\hline LC1: Regular waves & 0.14 & 1.333 & - \\
\hline LC1: Regular waves (full scale) & 8.4 & 10.33 & - \\
\hline LC2: Irregular waves & 0.133 & 1.49 & 2.87 \\
\hline LC2: Irregular waves (full scale) & 8 & 11.54 & 2.87 \\
\hline
\end{tabular}

For the calculation of the signal spectra for LC1 the measured data was concatenated to virtually increase the measurement length from about $80 \mathrm{~s}$ to $600 \mathrm{~s}$. For LC 2 no such step is done.

\section{Wave modelling}

Depending on the wave height, period and water depth one can distinguish between linear (Airy) waves and higher order wave theories. The datasets that have been modelled in this study fall in the category of second order Stokes waves (see Fig. 14). For evaluation of the impact

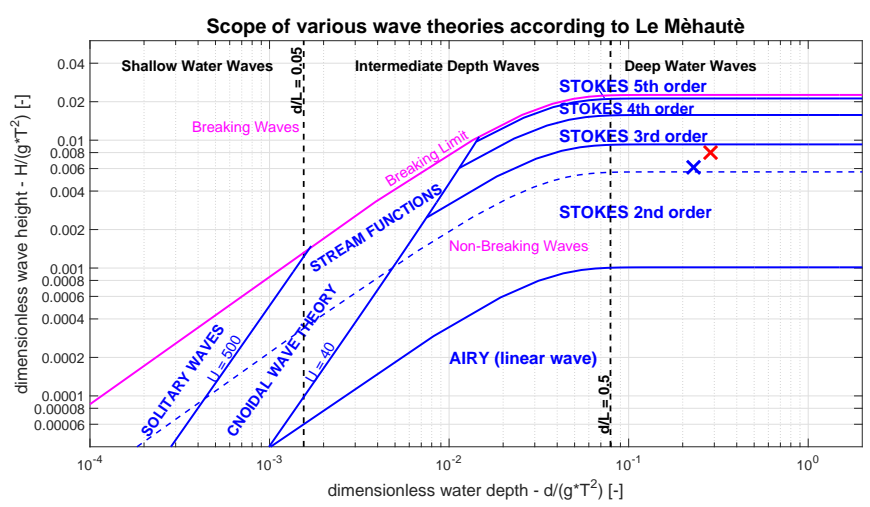

Fig. 14 Categorisation of wave theories according to Le Méhauté (1976) for model scale parameters, blue cross LC1, red cross LC2

of second order effects wave gauge measurements are compared to a simulation using HydroDyn as standalone model. Within the current release of HydroDyn v2.03.00c it is possible to use externally generated or measured wave-elevation time series, which will allow to simulate the wave excitation loads more properly. This new feature is not yet coupled to MBS and therefore the waves are still generated within HydroDyn.

For the modelling of irregular waves a JONSWAP spectrum is used. In comparison to linear waves deviations are present for the higher order wave kinematics (see Fig. 15). For this LC2 the upper cut-off frequencies for the second order terms is set at a frequency of $3 \mathrm{~Hz}$ in order to minimize the computational effort. Looking at regular waves one can see that the first peak is captured using linear waves. The second and third peak, however, require higher order wave theory (see Fig. 16). Second-order wave loads in potential-flow theory have not been considered yet leaving only second-order contributions to strip-theory solution (Morison). 


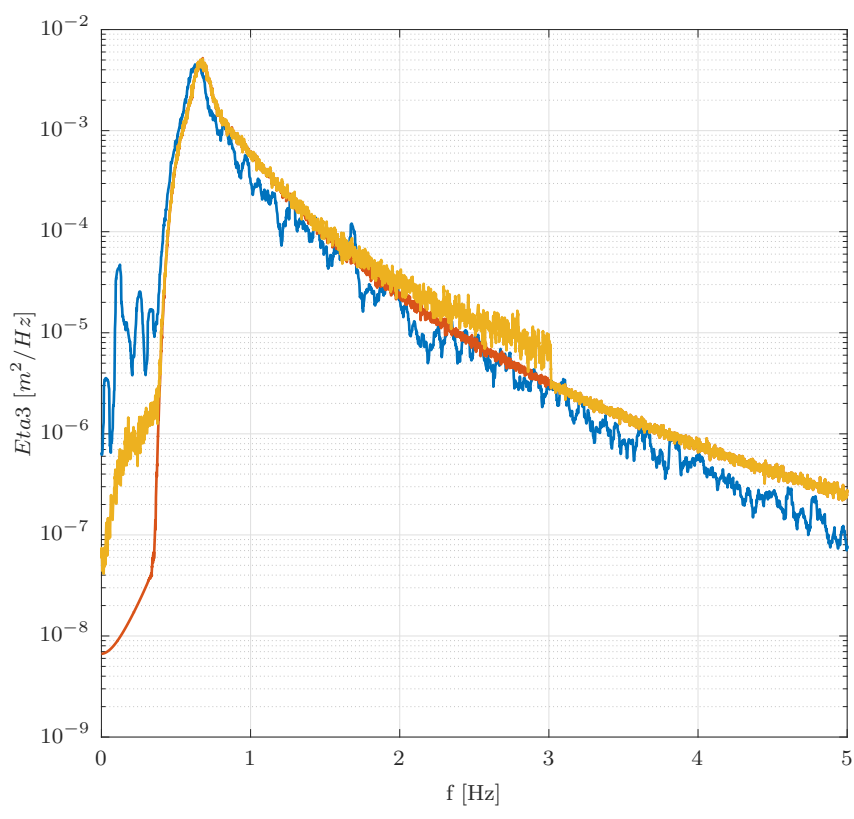

Fig. 15 LC2 wave probe 3 (Eta 3) frequency domain; blue: Measurement; red: Simulation 1.order waves; orange: Simulation 2.order waves

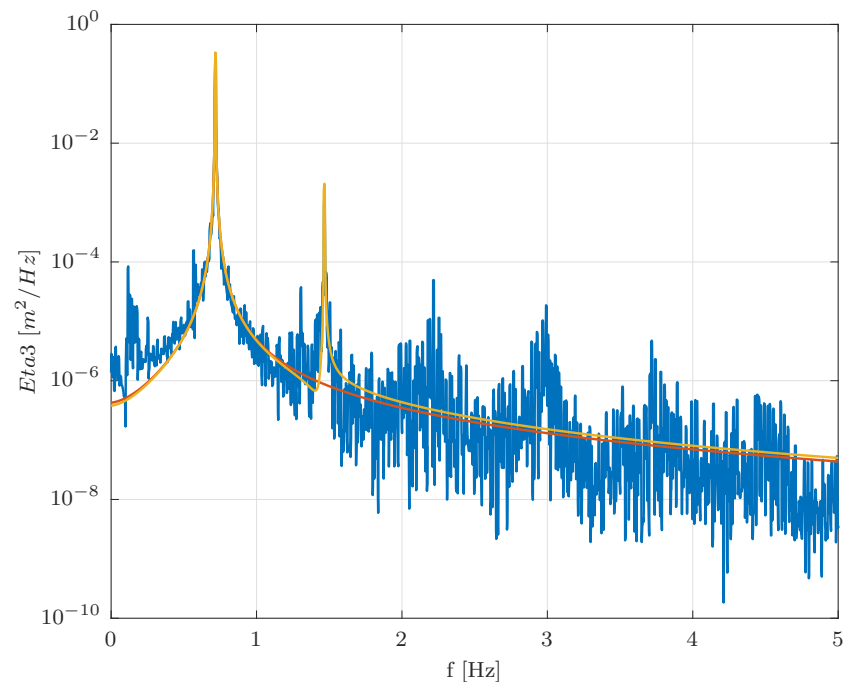

Fig. 16 LC1 wave probe 3 (Eta 3) frequency domain; blue: Measurement; red: Simulation 1.order waves; orange: Simulation 2.order waves

\section{Wind only}

Steady wind with the following parameters as summarized in Table 12 from test week two is analysed for the wind only test. The blade pitch angle was set to constant $0.7 \mathrm{deg}$ and the rotor speed was also hold constant at $71.3 \mathrm{rpm}$.

Table 12 Load cases wind only

\begin{tabular}{|l|c|c|}
\hline Testcase & wind speed $[\mathrm{m} / \mathbf{s}]$ & wind speed full scale $[\mathrm{m} / \mathbf{s}]$ \\
\hline Steady wind & 1.5 & 11.62 \\
\hline
\end{tabular}

\section{RESULTS AND DISCUSSION}

Within the pitch free decay test the simulation shows acceptable results without adding any additional terms $\left(B_{55}\right.$ damping and $C_{44}$ and $C_{55}$ stiffness). The mean pitch eigenfrequency can be determined to $0.2262 \mathrm{~Hz}$ which underestimates the measured values by around $3.0 \%$. The mean logarithmic decrement can be determined to 0.1075 , which underestimates the measured values by $32.1 \%$, the resulting mean damping ratio takes an amount of 0.0171 . Table 13 summarizes the mean values for the eigenfrequencies for the different simulation conditions and obtained damping values.

Table 13 Mean values for LC pitch free decay

\begin{tabular}{|l|c|c|c|c|}
\hline Testcase & Eigenfrequency [Hz] & log. decrement [-] & Damping ratio [-] & Damping constant \\
\hline Measurement data & 0.2333 & 0.1583 & 0.0252 & 11.4645 \\
\hline Simulation (no tuning) & 0.2262 & 0.1075 & 0.0171 & 7.5370 \\
\hline $\begin{array}{l}\text { Simulation (additional } \\
B_{55} \text { ) }\end{array}$ & 0.2262 & 0.1582 & 0.0252 & 11.093 \\
\hline $\begin{array}{l}\text { Simulation (additional } \\
\left.C_{44} C_{55} B_{55}\right)\end{array}$ & 0.2333 & 0.1557 & 0.0248 & 11.2631 \\
\hline
\end{tabular}

When adding the additional terms the damping characteristics of the platform can be simulated with very good results. When also the additional hydrostatic terms are considered the simulation is showing the same behaviour as the model in the wave tank.

In the time domain the following plots for the pitch sensor $\beta_{p}$ can be obtained for no additional, just damping additional and combined damping and hydrostatic additional terms, see Fig. 17.
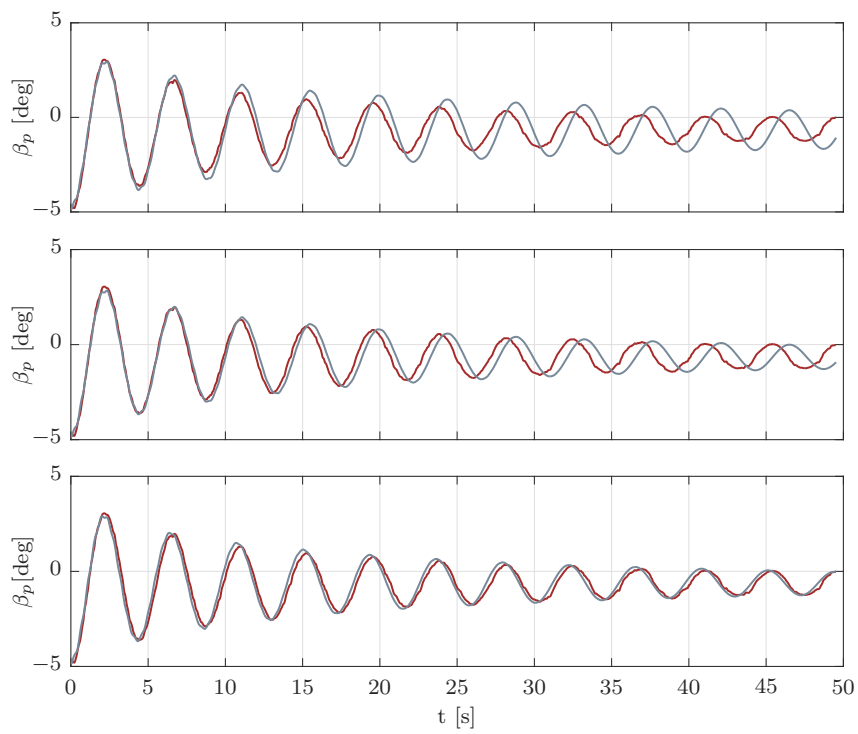

Fig. 17 Comparison of pitch free decay test case 1; red: Measurement; grey: Simulation; top: No additional terms; mid: with additional damping term $B_{55}$; bottom: with additional terms $B_{55}, C_{44}$ and $C_{55}$

\section{Waves only}

The waves for LC 1 and 2 were simulated with the additional tuning terms still applied ( $B_{55}$ damping and $C_{44}$ and $C_{55}$ stiffness). In Fig. 18 the comparison of the measurement data with the simulation data is shown for the wave probe sensor 3 (Eta3) and the pitch angle of the platform $\left(\beta_{p}\right)$ for this load case. During the data validation it is observed that for some load cases the wave probe sensors measure phase shifted values 
especially for larger wave heights. This might be caused due to a slight misalignment of the wave probe sensors. Wave probe sensor number 4 (WP\#4) which is parallel position to the undisplaced platform location (see Fig. 7) is not measuring reasonable values and therefore have to be neglected. For the here shown LC1 a phase shifting of $\Delta=40.5 \mathrm{deg}$ is applied for Eta 3.

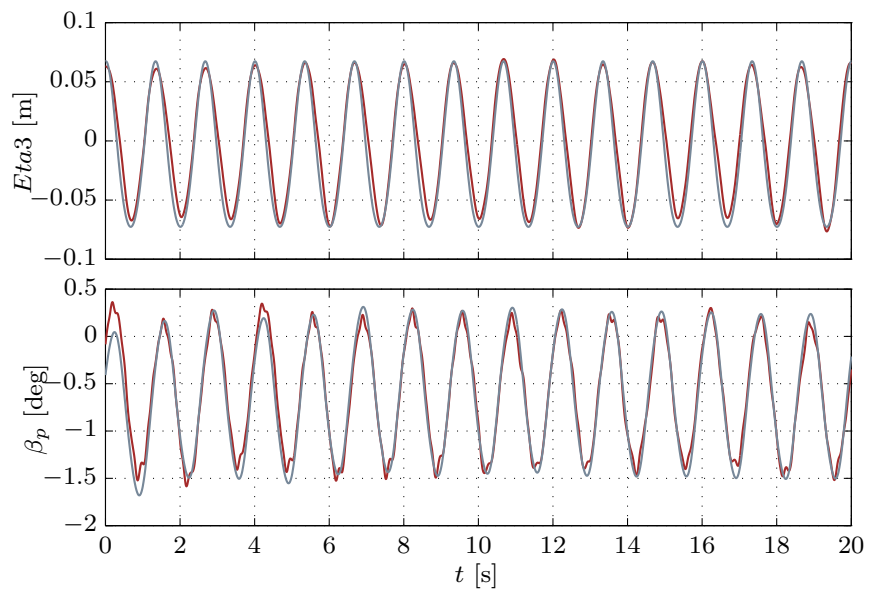

Fig. 18 LC1 regular wave (time domain); red: Measurement; grey: Simulation

The power spectral density (PSD) for the surge $x_{p}$, heave $z_{p}$ and pitch $\beta_{p}$ sensor shows that the motion amplitudes of the platform are underpredicted, even though the main frequencies are matching the measurement data (see Fig. 19).
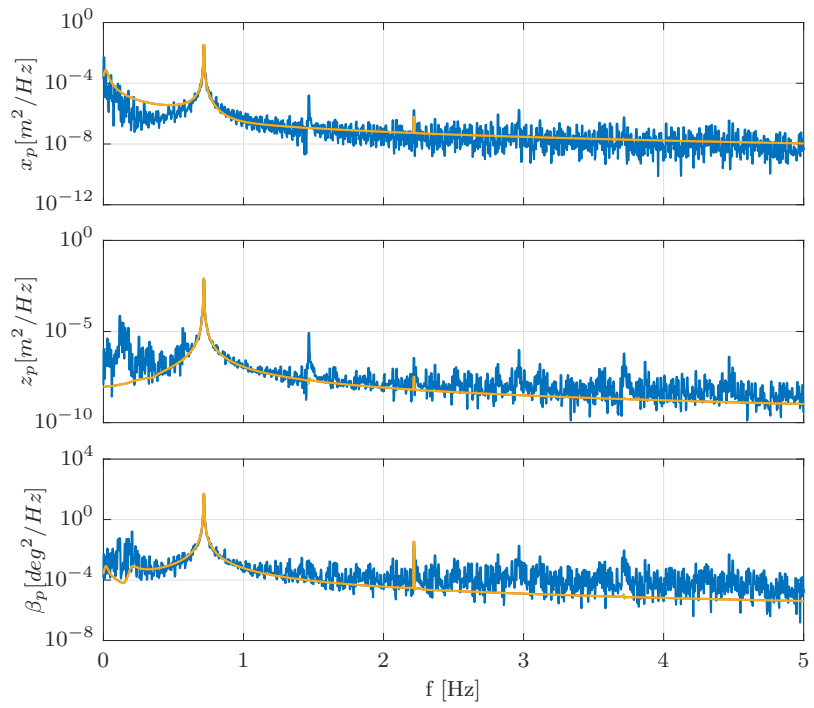

Fig. 19 PSD for LC1 regular wave (frequency domain); blue: Measurement data; red: Simulation 1.order; orange: Simulation 2.order

For the simulation of the irregular waves also the second order wave kinematics for the Morison drag term have to be considered in order to simulate the wave excitation properly.

With respect to the measurement data also a PSD comparison of surge $x_{p}$, heave $z_{p}$ and pitch $\beta_{p}$ motion is done (see Fig. 20). Also for LC2 the platform loads are not modelled correctly for low and high frequencies whereas at the main wave extinction the simulation shows the same
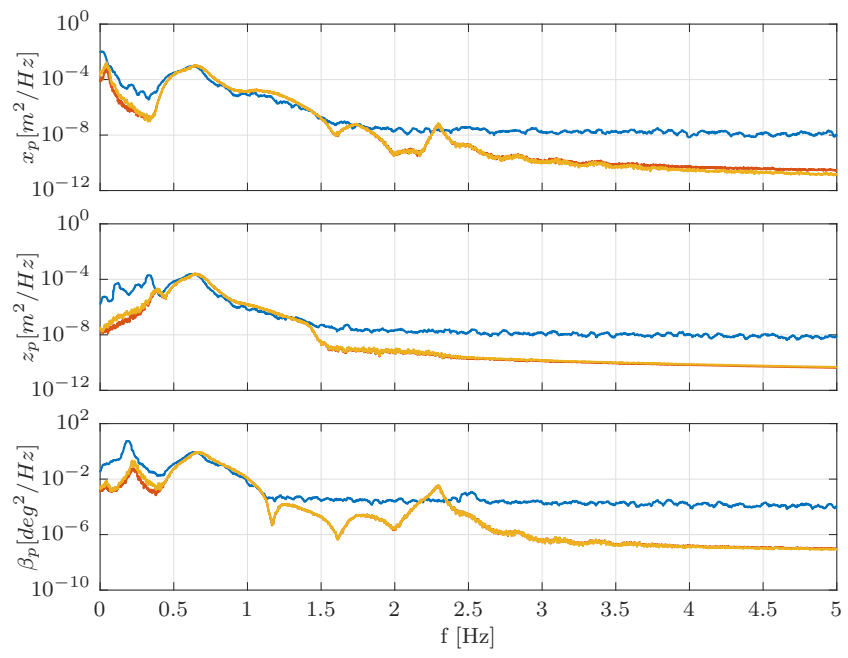

Fig. 20 LC2 surge, heave and pitch in frequency domain; blue: Measurement data; red: Simulation 1.order; orange: Simulation 2.order

results as the measured data.

\section{Wind only}

The analysed steady wind case delivered reasonable results for the displacement of the platform in surge, heave and pitch direction as well as for the tower base bending moments in fore-aft (FA) direction. The deviations are summarized in Table 14 with absolute and percentile values. Only in pitch direction a significant percentage deviation is observed. But when considering also the absolute deviations all the results show good agreement.

Table 14 Measurement and simulation values for steady wind

\begin{tabular}{|l|c|c|c|c|}
\hline Sensor & Measurement & Simulation & Absolute deviation & Percentage deviation \\
\hline Surge & $0.1980[\mathrm{~m}]$ & $0.2029[\mathrm{~m}]$ & $0.0049[\mathrm{~m}]$ & $+2.42[\%]$ \\
\hline Heave & $-0.2174[\mathrm{~m}]$ & $-0.2160[\mathrm{~m}]$ & $0.0140[\mathrm{~m}]$ & $-0.65[\%]$ \\
\hline Pitch & $2.9081[\mathrm{deg}]$ & $2.4898[\mathrm{deg}]$ & $-0.4183[\mathrm{deg}]$ & $-16.80[\%]$ \\
\hline Tower base bending FA & $15.5728[\mathrm{Nm}]$ & $15.6833[\mathrm{Nm}]$ & $0.1105[\mathrm{Nm}]$ & $0.71[\%]$ \\
\hline
\end{tabular}

\section{CONCLUSIONS}

This paper has summarized the key parameters and approaches of the INNWIND.EU scaled semisubmersible with a $10 \mathrm{MW}$ wind turbine. The original generic OC4-DeepCwind semisubmersible has been modified with additional ballast masses underneath the platform in order to obtain a correct overall center of mass. This is necessary because the nacelle with its blade pitch and torque actuators is heavier than the scaled nacelle. Free-decay experiments of the moored platform were validated successfully before results with regular and irregular waves were analysed. At the end also wind only test with steady wind were validated successfully. The good agreement of the coupled SIMPACK model shows that first, the model is validated to the extent of the compared load cases and second, the dataset is valid to be used in further projects. It is planned to make the data publicly available in the near future. Thus, it can be seen as another dataset for the OC4 DeepCwind model that has been previously tested. With these redundant sets of results uncertainty of scaled tests can be assessed and reduced and the experience with combined wind-and-wave tests shared and spread in industry and research. 


\section{ACKNOWLEDGMENTS}

The research leading to these results has received partial funding from the European Communitys Seventh Framework Programme FP7-ENERGY2012-1-2STAGE under grant agreement No. 308974 (INNWIND.EU). The experiments have been carried out at the LHEEA facility at Ecole Centrale de Nantes (ECN)/(France) funded by the European CommunityResearch Infrastructure Action FP7 "Capacities" specific program MARINET. The authors would like to thank also the staff of ECN for there assistance during the tests.

\section{REFERENCES}

Amann, F (2014). Skalierung, Auslegung und Konstruktion eines Modells einer schwimmenden Windkraftanlage, Master's thesis, University of Stuttgart.

Arent, D, Sullivan, P, Heimiller, D, Lopez, A, Eurek, K, Badger, J, Jorgensen, H, and Kelly, M (2012). "Improved offshore wind resource assessment in global climate stabilization scenarios," .

Bredmose, H, Larsen, SE, Matha, D, Rettenmeier, ME, A., and L., $S$ (2012). "MARINET D 2.4: Collation of offshore wind-waves dynamics," Technical report, Marine Renewables Infrastructure Network for Emerging Energy Technologies (MARINET).

Coulling, A, Goupee, A, Robertson, A, and Jonkman, J (2013). "Importance of second-order difference-frequency wave-diffraction forces in the validation of a fast semi-submersible floating wind turbine model," in Proceedings of the ASME 2013 32nd International Conference on Ocean, Offshore and Arctic Engineering, pages 110.

Craig, H and Laino, DJ (2002). "User's guide to the wind turbine aerodynamics computer software aerodyn," Technical report.

DNV-GL (2013). "Position Mooring- Offshore Standard DNV-OSE301,".

Fukushima Offshore Wind Consortium (2016). "Fukushima forward wind project," in http://www.fukushima-forward.jp/english/ research/index.html Accessed: 05.01.2016.

Gueydon, S (2015). "Verification of the second-order wave loads on the oc4-semisubmersible," in EERA Deepwind, Trondheim/NO.

Gueydon, S (2016). "Aerodynamic damping of a HAWT on a semisubmersible," in EERA Deepwind, Trondheim/NO.

Gueydon, S, Duarte, T, and Jonkman, J (2014). "Comparison of second-order loads on a semisubmersible floating wind turbine," in Proceedings of the ASME 2014 33rd International Conference on Ocean, Offshore and Arctic Engineering, San Francisco, USA.

Gueydon, S, Venet, G, and Fernandes, G (2015). "Influence of the rotor characterization on the motion of a floating wind turbine," in Proceedings of the ASME 2015 34th International Conference on Ocean, Offshore and Arctic Engineering, Saint John's/Canada.

Huijs, F, Ridder, EjD, and Savenije, F (2014). "Comparison of model tests and coupled simulations for a semi-submersible floating wind turbine," in Proceedings of the ASME 2014 33rd International Conference on Ocean, Offshore and Arctic Engineering, San Francisco, USA.

Jain, A, Robertson, A, Jonkman, J, Goupee, A, Kimball, R, and Swift, AH (2012). "Fast code verification of scaling laws for deepcwind floating wind system tests," in Proceedings of the Twentysecond (2012) International Offshore and Polar Engineering Conference, volume 4, pages 355-365, Rhodes.
Jonkman, J, Robertson, A, and Hayman, G (2013). "HydroDyn Users Guide and Theory Manual," Technical report, National Renewable Energy Laboratory- NREL.

Kimball, R, Goupee, A, Fowler, M, Ridder, EJD, and Helder, J (2014). "Wind/wave basin verification of a performance-matched scale-model wind turbine on a floating offshore wind turbine platform," in Proceedings of the ASME 2014 33rd International Conference on Ocean, Offshore and Arctic Engineering, San Francisco, USA.

Le Méhauté, B (1976). An introduction to hydrodynamics and water waves, Springer Verlag New York.

Lemmer, F, Azcona, J, Matha, D, Amann, F, Campagnolo, F, Bredmose, H, and Montinari, P (2014). "INNWIND.EU D4.24: Floating wind model tests ecole centrale de nantes 2014," Technical report, INNWIND.EU.

Make, M, Vaz, G, Fernandes, G, Burmester, S, and Gueydon, S (2015). "Analysis of aerodynamic performance of floating wind turbines using cfd and bemt methods," in Proceedings of the ASME 2015 34th International Conference on Ocean, Offshore and Arctic Engineering, Saint John's/Canada.

Masciola, M (2016). "Map++ Documentation Release 1.15," Technical report, National Renewable Energy Laboratory-NREL.

Moriarty, PJ and Hansen, C (2005). AeroDyn Theory Manual, December.

Musial, W, Butterfield, S, and Ram, B (2006). "Energy from offshore wind," Technical report, National Renewable Energy Laboratory-NREL.

Ridder, EJD, Otto, W, Zondervan, GJ, Huijs, F, and Vaz, G (2014). "Development of a scaled-down floating wind turbine for offshore basin testing," in Proceedings of the ASME 2014 33rd International Conference on Ocean, Offshore and Arctic Engineering, San Francisco, USA.

Robertson, A, Goupee, A, Jonkman, J, Prowell, I, Molta, P, Coulling, A, and Masciola, M (2013). "Summary of conclusions and recommendations drawn from the DeepCwind scaled floating offshore wind system test campaign," in Proceedings of the ASME 2013 32nd International Conference on Ocean, Offshore and Arctic Engineering, pages 1-13.

Robertson, A, Jonkman, J, Masciola, M, Song, H, Goupee, A, Coulling, A, and Luan, C (2014). "Definition of the semisubmersible floating system for phase II of OC4," Technical report, NREL, Boulder/USA.

Statoil ASA (2014). "Hywind Demo Project," in http: //www.statoil.com/en/TechnologyInnovation/NewEnergy/ RenewablePowerProduction/Offshore/Hywind/Pages/ HywindPuttingWindPowerToTheTest.aspx Accessed: 03.01.2016. 